\title{
O CÓDIGO DE PROCESSO CIVIL DE 2015 E OS TEMPOS HIPERMODERNOS DO PROCESSO E DA JURISDIÇÃo
}

\section{Guilherme Christen Möller*}

Resumo: Tendo por objetivo analisar o conceito de Processo e de Jurisdição na perspectiva da Hipermodernidade, para que se possa responder ao problema proposto para esta pesquisa, a insuficiência daquela concepção clássica de Processo e de Jurisdição na atual realidade social, utilizando-se de uma metodologia de pesquisa dedutiva, ao final dos dois capítulos propostos para este estudo, conclui-se que a atual concepção de Processo refere-se ao Hiperprocesso: uma fragmentação processual dada à perda de uma unidade central do processo, em sua perspectiva extrajudicial, e a ampliação das formas de resolução de conflitos como garantia à tutela jurisdicional, em sua perspectiva judicial.

Palavras-chave: Direito; Processo; Jurisdição; Cultura; Hipermodernidade.

\section{THE CODE OF CIVIL PROCEDURE OF 2015 AND THE HIPERMODERNS'S TIMES OF THE PROCESS AND OF THE JURISDICTION}

\begin{abstract}
With the objective to analyzing the concept of Process and Jurisdiction in the perspective of Hypermodernity, to answer the problem proposed for this research, the insufficiency of that classical conception of Process and Jurisdiction in the current social reality, using a deductive research methodology, at the end of the two proposed chapters for this study, it's concluded that the current conception of Process refers to Hyperprocess: a procedural fragmentation due to the loss of a central processing unit, in its out-of-court perspective, and

\footnotetext{
* Mestrando em Direito Público pelo Programa de Pós-Graduação em Direito da Universidade do Vale do Rio dos Sinos (UNISINOS). Bolsista do Programa de Excelência Acadêmica (PROEX) da Coordenação de Aperfeiçoamento de Pessoal de Nível Superior (CAPES). Bacharel em Direito pela Universidade Regional de Blumenau (FURB). Membro do Instituto Brasileiro de Direito Processual (IBDP) e da Associação Brasileira de Direito Processual (ABDPro). Autor de livros e de mais de duas dezenas de artigos científicos relacionados ao Direito Processual Civil. Advogado e Consultor Jurídico. Currículo Lattes: http://lattes.cnpq.br/0168074867678392. Endereço postal: Programa de Pós-Graduação em Direito da Universidade do Vale do Rio dos Sinos (UNISINOS) - São Leopoldo (RS). E-mail: guilhermecmoller@gmail.com.
} 
the extension of forms of conflict resolution as guarantee to the judicial protection, in its judicial perspective.

Keywords: Law; Process; Jurisdiction; Culture; Hypermodernity.

\section{INTRODUÇÃO}

Permeando-se os ensinamentos de grandes processualistas como Michele Taruffo, Ovídio Araújo Baptista da Silva, José Joaquim Calmon de Passos, Enrico Tullio Liebman, Francesco Carnelutti, Piero Calamandrei, Giuseppe Chiovenda, dentre tantos outros que muito honram o legado da ciência processual civil na história da humanidade com as suas contribuições teóricas, percebe-se que o ponto que não se pode deixar à limiar ao dedicar-se ao estudo da ciência processual é o fato de que ela deve representar os reais anseios e desejos da sociedade. Porém, partindo-se da hermenêutica gadameriana, sabe-se que há, no tempo, um processo cíclico e infinito de buscar-se a partir de uma determinada realidade o sentido de algo, e, este algo relacionado a este estudo, refere-se, de forma direta, à sociedade, e, de forma indireta, ao Processo. De fato, se é no Processo que se vê o retrato da sociedade, será a partir da investigação pelo sentido que se deve atribuir à sociedade que se poderá obter um conceito de Processo; eis a proposta deste artigo.

Ao buscar uma descrição atualizada do mundo, vê-se a emergência de situações que, em contrapartida às suas perspectivas passadas, soam demasiadamente inusitadas; assim, por exemplo, está a ideia de um relacionamento familiar poliamoroso, ou seja, de uma família que, mesmo que sua composição se dê por uma pluralidade superior a duas pessoas, assim passam a autoreconhecer-se (independente da anuência estatal sobre essa característica no instituto familiar), ou ainda, dos bitcoins, uma moeda sem qualquer espécie de vínculo estatal, afinal, opera-se a partir da internet, e que é admitido em inúmeros países; enfim, aqui poderiam ser citados os casos do webnamoro, homeoffice, sistema de entrega de objetos via drones (como tem sido uma prática comum da Amazon nos Estados Unidos da América), enfim, esta lista meramente exemplificativa mostra-se como fundamento para sustentar a ideia de que se vive, atualmente, numa sociedade caracterizada por sua desorientação, a qual será denominada pelo filósofo francês Gilles Lipovetsky por "Hipermoderna". Culminou-se num momento em que os valores sociais passaram a adquirir uma roupagem estendida, de modo que se perde as balizas 
entre o mínimo e o máximo acerca dos institutos da sociedade. Atualmente, a sociedade é caracterizada por uma elevação da sua carga de complexidade para uma dimensão jamais presenciada em toda a história da humanidade. A partir dessa constatação é que se quer observar o atual conceito de Processo e de jurisdição.

Para que se possa alcançar ao objetivo proposto para este estudo, a divisão deste trabalho conta com dois momentos. No primeiro capítulo, será analisada a relação umbilical entre a Cultura e o Processo, mas precisamente, analisando-se a concepção de Processo a partir do movimento de transição dos estágios socioculturais da Modernidade Líquida do sociólogo polonês Zygmunt Bauman, para o estágio sociocultural da Hipermodernidade de Gilles Lipovetsky. No segundo momento deste estudo, com base em toda a análise realizada no primeiro capítulo, será buscado apresentar um conceito de Processo e de Jurisdição na perspectiva da atual concepção sociocultural da sociedade, o estágio Hipermoderno. Tem-se como a hipótese deste estudo que ao trabalhar com a temática Hipermodernidade e Processo, obtêm-se a ideia de um Hiperprocesso e de uma hiperjurisdição; o Hiperprocesso pode ser visto sob a ótica judicial e extrajudicial, de modo que, enquanto a sua ótica extrajudicial está relacionada à uma fragmentação processual dada a perda de uma unidade central do Processo, especialmente diante de uma elevação dos níveis de complexidade da sociedade, a sua faceta judicial está representada pela ampliação cognitiva da garantia fundamental de acesso à ordem jurídica, a qual, para fornecer uma concepção igualmente complexa à realidade da sociedade, passa a admitir o desenvolvimento da garantia à tutela jurisdicional por vias de outras formas de resolver os conflitos, contanto que chanceladas pelo Estado.

\section{CULTURA, PROCESSO, ZYGMUNT BAUMAN E GILLES LIPOVETSKY: A BUSCA PELA CONCEPÇÃO ATUAL DE PROCESSO A PARTIR DA INVESTIGAÇÃO DA MUTAÇÃO DA SOCIEDADE}

Quiçá, a tarefa mais árdua para todos aqueles pesquisadores que se dedicam a estudar o Processo seja conceitua-lo. A dimensão de tal tarefa não poderia ser outra, afinal, sua concepção poderá variar conforme uma pluralidade de elementos; eis o caráter complexo do conceito de Processo. Exemplificando-se, haveria, portanto, como conceituar o processo a partir de uma raiz jusnaturalista - o caso daquele Processo da Idade Média, como lembra Enrico 
Tullio Liebman (2005) -, e nessa mesma linha, conceitua-lo a partir das raízes positivistas baseando-se em Lenio Luiz Streck (2017), o caso da Europa no período renascentista - e, partindo-se da ideia de Karl Popper (2010), pós-positivistas. Além do anteriormente exposto, tal concepção ora pretendida apresenta respostas variáveis a considerar um específico sistema jurídico ${ }^{1}$ - ou seja, se civil law, se common law, dentre outros sistemas jurídicos híbridos. Ainda, sem dúvida que o fator "tempo" muito importa para a obtenção de tal conceito, afinal, como nos lembra Gadamer (2005) $)^{2}$, o tempo permite uma expressão completa do verdadeiro sentido que há em algo, mas não esgotado quando se chega a tal final; afinal, há aqui um processo infinito. Em síntese, todos estes apontamentos iniciais exemplificativos mostram que esta discussão é realmente complexa e, ao que tudo indica, está longe de encontrar uma conclusão.

O ponto que se quer chegar com tais apontamentos feitos acima é que, inobstante à perspectiva (com as devidas ressalvas à matriz jusnatural) que se adota para buscar um conceito de Processo, há um inegável denominador comum em todos: o ser humano. Ao questionar-se sobre o porquê de o Processo existir, observa-se que ele, em verdade, não conta com uma derivação natural, outrossim, ele nada mais é do que um produto social; ou seja, seguindo-se na ideia de Ribeiro (2010), Cícero (1967) e Carnelutti (2007), o Processo é feito pelos humanos para os servi-los. Com este apontamento, torna-se mais acessível a ideia de contemplar a sua variação conforme uma determinada orientação desses seres humanos. O que determinará essa orientação é a soma de elementos como valores, crenças, símbolos, tradições, etc., ou seja, a própria noção que se tem pela Cultura, afinal, como lembra Oscar G. Chase (2014) em sua exposição variada daquela distinção dada por Melford E. Spiro (1994) acerca da Cultura, ela é, senão, a observação de uma soma de práticas e valores particulares de uma comunidade. Portanto, toda a construção até então desenvolvida neste trabalho permite concluir no mesmo

\footnotetext{
${ }^{1}$ Para um aprofundamento neste sentido: Cf. MERRYMAN, John Henry; PÉREZ-PERDOMO, Rogelio. A tradição da civil law: uma introdução aos Sistemas Jurídicos da Europa e da América Latina. Trad. Cássio Casagrande. Porto Alegre: Sergio Antonio Fabris Editor, 2009.

${ }^{2}$ Ainda, na temática Direito e tempo: Cf. FRANÇOIS, Ost. O tempo do Direito. Lisboa: Instituto Piaget, 2001; e, Cf. TEIXEIRA, Anderson Vichinkeski; GUIMARÃES FILHO, Gilberto. Tempo e Direito: reflexões sobre a temporalização da Constituição a partir de Paul Ricoeur e François Ost. Revista Culturas Jurídicas (RCJ), vol. 1, n. 1, 2014. p. 99-116. Disponível em: <http://andersonteixeira.com/data/documents/Artigo-AVT-e-GGFTempo-e-Direito.pdf>. Acesso em: 31 jan. 2019.
} 
sentido apresentado por Galeno Lacerda (2008), ou seja, de que o Processo nada mais é do que um produto que deriva da cultura humana ${ }^{3}$.

Da conclusão pretérita, partindo-se para a história, ela demonstra que a humanidade passou por diversos ciclos socioculturais, cada qual transmitindo a sua configuração de um determinado período; assim, por exemplo, pegue-se o caso da cultura na sociedade da Idade Média, lembrada por Hermann Heller (1968), em que, seguindo-se na proposta de Ingo Wolfgang Sarlet (2017), se havia uma forte presença do poder da Igreja sobre àquela concepção primitiva de "Estado" diante da inexistência de uma autoridade central, a cultura neste determinado estágio sociocultural partia daquela essência filosófica da dogmática religiosa, ou seja, da fé cristã. Todos os institutos sociais eram calcados nesta visão cultural; fazia-se ou deixava-se de fazer algo senão em nome de Deus. O próprio Direito (e o Processo) estava agregado à uma maneira canônica; condenava-se ou não algo em nome de Deus, mais além, cumprir a lei era cumprir a própria vontade de Deus ${ }^{4}$. Entretanto, junto ao movimento renascentista do século XVI estava o início da uma nova concepção de cultura, a qual, agora, relacionada à maneira racionalista do ser humano de René Descartes (2011). Neste novo ciclo cultural, passou-se a superar àquela concepção da dogmática religiosa pela essência de uma racionalidade das coisas. Isso, no entanto, vai além do campo da metafísica de René Descartes (2016), afinal, os próprios institutos sociais passaram a ser remodelados conforme essa nova concepção de cultura, desde a matemática (com a Geometria Analítica) para até a própria estrutura de um Estado Monárquico - como lembra Luciano Gruppi (1996), ao trabalhar com a ideia de "o príncipe" de Nicolau Maquiavel (2005) -, absolutamente tudo passou por uma redefinição de sentidos; o Direito e o Processo adquiriram essa roupagem racionalista da Idade Moderna, como pode-se observar com a transição daquele direito jusnaturalista da Idade Média para um direito, num primeiro momento, jusracionalista (ainda banhada numa ideia jusnatural)

\footnotetext{
${ }^{3}$ Partindo-se da ideia de Oscar G. Chase (Direito, Cultura e Ritual: sistemas de resolução de conflitos no contexto da cultura comparada. Trad. Sergio Arenhart e Gustavo Osna. São Paulo: Marcial Pons, 2014), deve-se fazer uma breve observação acerca dessa afirmação. Não só a Cultura poderá formar do Direito (e o Processo), afinal, o caminho inverso também é possível. Para o caso do Brasil, um grande exemplo desta análise inversa é o Código de Defesa do Consumidor, Lei n. ${ }^{\circ} 8.078$, de 11 de setembro de 1990.

${ }^{4}$ Para observar o panorama do Direito neste estágio sociocultural, cf. exemplo dado por Vicente de Paulo Barretto (O paradigma ecológico e a teoria do direito. In: STRECK, Lenio Luiz; ROCHA, Leonel Severo; ENGELMANN, Wilson (orgs.). Constituição, Sistemas Sociais e Hermenêutica: Anuário do Programa de PósGraduação em Direito da UNISINOS: Mestrado e Doutorado. n. 13. p. 227-245. Porto Alegre: Editora Livraria do Advogado, 2017) nas páginas 230 e 231 de seu capítulo do Anuário do Programa de Pós-Graduação em Direito da UNISINOS do ano de 2017.
} 
e, a posteriori, lembrado por Streck (2017), as primeiras manifestações juspositivistas do mundo em países como Inglaterra, França e Alemanha. Desse exemplo, eis o ponto que se buscou chegar com toda a exposição até então desenvolvida: como a Cultura do século XXI é caracterizada e, com isso, como ela opera em relação ao Direito e ao Processo?

Para que se possa responder esse ponto, deve-se destacar que há na cultura do século XXI uma intrínseca relação para com o movimento de derretimento da sociedade do século XX. Sabe-se que o mundo não parou no século XVI. De lá para cá diversos eventos históricos tanto eventos históricos positivos (revolução industrial ${ }^{5}$, globalização ${ }^{6}$, etc.), quanto negativos (Guerras Civis e Mundiais ${ }^{7}$ ) - contribuíram para a transformação dos diversos institutos da sociedade. Nesse sentido, pegue-se, por exemplo, as relações de trabalho do século XVIII em que houve o início da primeira revolução industrial - a qual é caracterizada pela inserção de máquinas no mercado de trabalho. As manufaturas daquela época passaram, paulatinamente, a serem substituídas por grandes industrias em que a tarefa desempenhada pelo homem artesão passou a ser desenvolvida por uma máquina. No mesmo campo, porém, avançando-se para o século XX, o avanço na tecnologia, especialmente no período da Guerra Fria, permitiu que hoje um médico possa realizar uma cirurgia de forma remota, ou seja, independente do espaço de distância entre este profissional e seu paciente. A forma de comunicação entre as pessoas evolui de mesma forma. É curioso pensar que aplicativos para smartphones como o WhatsApp ou o Facebook foram capazes de suprimir a necessidade de aguardar dias, semanas ou até mesmo meses para o recebimento de uma carta via postagem em correio. Eis a análise dada pelo sociólogo polonês Zygmunt Bauman.

Zygmunt Bauman (2001) observa que houve uma desarmonização entre o tempo e a distância. A instantaneidade das comunicações fez com que a distância se tornasse obsoleta. $O$ tempo passa a ser a principal preocupação da sociedade nomeada por Bauman (2013) como sendo líquida. A razão permanece como a essência deste novo estágio sociocultural, entretanto, ela passa a adquirir uma característica plástica. A cultura, sob a ótica da razão líquida é vista a medida em que se observam que os institutos da sociedade não mais contam com àquela rigidez da Idade Moderna; eles, de forma paulatina, transformam-se em líquidos. Assim, nesta ótica

${ }^{5}$ Cf. SILVA, Kalina Vanderlei; SILVA, Maciel Henrique. Dicionário de Conceitos Históricos. 3. ed. São Paulo: Contexto, 2018.

${ }^{6}$ Cf. FRIEDMAN, Thomas L. O mundo é plano: uma breve história do século XXI. São Paulo: Companhia das Letras, 2014.

${ }^{7}$ Cf. GILBERT, Martin. A história do século XX. Trad. Carolina Barcellos e Ebreia de Castro Alves. São Paulo: Planeta, 2016. 
cultural, não há mais a possibilidade de delimitarem-se os institutos da sociedade a partir de pressupostos lógicos, disjuntos, reducionistas (contrariando a razão em sua forma sólida). Essa plasticidade da razão líquida que se refere neste momento permite que surjam diversos moldes para os institutos da sociedade. Trabalhando-se nessa perspectiva da plasticidade da razão líquida, pegue-se o caso das famílias; passasse daquela concepção clássica de família - cuja composição se dá por homem, mulher e filhos - para famílias; assim, começa-se a admitir que o instituto da família tenha molde diverso em relação àquela tradicional, daí surgindo a possibilidade de que a sua composição se dê por dois homens, duas mulheres, com ou sem filhos, bem como a sua composição a partir dos mais diversos gêneros sexuais que existem. Esse caráter líquido é igualmente visto no Direito e no Processo; no Direito, pegue-se o Recurso Especial (REsp) n. 1.713.167 (2017/0239804-9), no qual colocou-se a conhecimento do Superior Tribunal de Justiça (2017) brasileiro a discussão sobre a guarda de um animal doméstico - apenas para melhor elucidar o caso apresentado, a discussão no referido processo versava acerca de uma dissolução de união estável em que uma das partes havia pleiteado a regulamentação de visitas de "Kimi”, a cadela da raça Yorkshire do ex-casal; no Processo, pegue-se como exemplo o caso dos negócios jurídicos (art. 190) ${ }^{8}$ do Código de Processo Civil de 2015, ou seja, a possibilidade de que as partes possam estipular mudanças no procedimento desse seu processo, possibilitando, assim, que o procedimento se ajuste conforme as especificidades da causa - assim, questões como os ônus processuais, os poderes e os deveres dessa relação jurídica, dentre outros temas, não mais sigam aquele padrão estipulado por uma codificação. O Direito e o Processo da Modernidade Líquida começam a caminhar em sentido contrário àquela disjunção, àquela ideia reducionista, da proposta pela filosofia de René Descartes. Observa-se que a complexidade retoma à ciência, ou melhor - seguindo-se na ideia de Ernildo Stein sobre a complexidade estar no olhar e não naquilo que se observa -, permitese, como lembra Edgar Morin (2015), que a sociedade retome o seu olhar complexo sobre ela. Ocorre, no entanto, que esse movimento de liquidez, mesmo que de forma indireta, influirá para uma nova concepção de razão, a qual passará para a sua forma estendida: um novo estágio sociocultural da humanidade. A razão passa a ser estendida posto que os valores da sociedade

\footnotetext{
${ }^{8}$ Sobre a temática "negócios jurídicos": Cf. ALVIM WANBIER, Teresa Arruda; DIDIER JR., Fredie; TALAMINI, Eduardo; DANTAS, Bruno. Breves comentários ao novo Código de Processo Civil. 3. ed. rev. e atual. de acordo com a Lei 13.256/2016 (Admissibilidade dos recursos), Lei 13.146/2015 (Estatuto da Pessoa com Deficiência), Lei 13.140/2015 (Lei de Mediação), Lei 13.129/2015 (Lei de Arbitragem). São Paulo: Editora Revista dos Tribunais, 2016.
} 
passam a ser estendidos (amplos). Não mais é possível encontrar um denominador comum para os diversos institutos e elementos da sociedade. Como exemplo dessa nova transformação cultural da sociedade - e seguindo-se no exemplo das famílias para a melhor compreensão deste ponto - pegue-se as famílias cuja a composição se dá de forma plural, no caso o poliamor.

Dada a dimensão que a razão vem tomando, ou seja, ampliando-se cada vez mais, atualmente não mais há a possibilidade de que se fixe parâmetros mínimos e máximos sobre os institutos da sociedade. Nesse sentido, dando seguimento ao exemplo do poliamor, ele nada mais seria do que a representação do que se afirmou, afinal, ao buscar conceituar família em pleno ano de 2019, coloca-se diante de um paradoxo, visto que ela pode ser composta tanto de forma individual, quanto de forma plural. Ou seja, o conceito de família no pós-derretimento da sociedade deverá levar em conta que ela se manifesta desde aquela forma tradicional da Modernidade Sólida - homem + mulher - , bem como homoafetiva - homem + homem; mulher + mulher - e, nessa linha, dar-se conforme orientação respectiva dos diversos gêneros sexuais existentes; ainda, poderia ela ser configurada pela multiplicidade de indivíduos que a compõe (poliamor) - homem + homem + mulher + mulher + homem + mulher... - , enfim, a infinidade de exemplos que aqui poderiam ser apresentados mostra que, após o início do estágio sociocultural líquido da modernidade, há uma forte tendência de que a sociedade seja cada vez mais abstrata, o que se dá diante do aumento da sua carga de comunicação (complexidade). Parece que há uma demasiada procura pelos limites dessa sociedade, de modo que quanto mais se busca tal objetivo, mais ampla ela vem se tornando; justamente, de líquida, a razão se transformou em estendida.

Essas transformações dos institutos da sociedade para uma forma mais ampla são vistas na tese defendida pelo filósofo francês Gilles Lipovetsky (2018) sobre a Hipermodernidade. Utilizando-se como base de sua reflexão o mercado de consumo da moda e a ideia de um hiperconsumo, Lipovetsky observa que a cultura de hoje é formada a partir de uma tríplice caracterização: o mercado (capitalismo); a tecnologia; e, o indivíduo. Sob a perspectiva do mercado, a cultura do mundo estendido caracteriza-se pela transição do capitalismo, a partir da década de 80, para um novo ciclo: o Hipercapitalismo; em síntese, o principal pilar deste novo ciclo do capitalismo refere-se ao seu caráter liberal, o que se evidencia pelo forte desmantelamento daqueles antigos controles de limitação do mercado de concorrência no mercado global; o Hipercapitalismo refere-se ao inchaço da economia e da bolsa de valores, a questão principal do capitalismo centra-se no poder das finanças e do poder 
dos grandes investidores. Na vertente tecnológica da nova cultural, o filósofo francês sustenta que há uma transição da política para tecnologia sobre o domínio da vida humana. O mundo passa a ter a tecnologia como o centro de seu cotidiano; ela se estende a todos os domínios da vida, de modo que os seres humanos se tornam os reféns da tecnologia. A terceira característica da concepção de cultura após os tempos líquidos refere-se ao indivíduo. Gilles Lipovetsky, neste específico ponto, observa que àquela concepção clássica de individualismo do século XVIII, ou seja, como sendo um sistema de valores capaz de posicionar o indivíduo livre e igual como sendo o valor central da cultura da sociedade, passa por um processo de expansão, adquirindo a roupagem de um hiperindividualismo, o qual está centrado na ideia de um modelo caracterizado pela sua desorientado, em que se dá ênfase as realizações próprias, distante, portanto, das diversas imposições coletivas da sociedade. As junções desses três principais elementos formarão a concepção da cultura nos tempos em que a razão passa a assumir a sua forma estendida; nos tempos Hipermodernos da humanidade. (LIPOVETSKY; SERROY, 2011).

Para demonstrar a sua visão sobre a Hipermodernidade, Gilles Lipovetsky (2007), utilizando-se do exemplo da moda, destaca que na medida em que o mundo se torna amplo, ampliaram-se os referenciais da moda, o que acabará resultando na incerteza desses múltiplos referenciais e de suas respectivas seguranças estéticas/sanitárias. A desorientação social causada pelo hiperindividualismo afastará àquela concepção das normas e referências coletivas - o alto e o baixo, o bom gosto e o mau gosto, o vulgar e o elegante, o chique e o casual -, instituindo, portanto, um sistema calcado na pluralidade e desregulação. A marca, no cenário da moda, exercerá a função de representar a destradicionalização da moda, a impulsividade humana na Era do novo individualismo, as incertezas dos tempos dos valores amplos. A moda nos faz perceber que sem que nos déssemos conta, o mundo se tornou Hiper. Atualmente, e cada vez mais, vê-se a busca pelo melhor - o que não necessariamente deverá corresponder ao maior, afinal, o maior apenas é o melhor na perspectiva da Modernidade Sólida -: o melhor carro, a melhor roupa, o melhor computador, o melhor smartphone, a melhor viagem, o melhor vinho, o melhor café, a melhor aparência, e assim sucessivamente. Assim, Hipermodernidade refere-se à um estágio sociocultural da humanidade que enaltece a desorientação do amplo, justamente aquilo que se está vivendo após o processo de derretimento do mundo. A despadronização completa dos institutos da sociedade é a manifestação pura de que a 
humanidade conseguiu desvencilhar-se, em sua maioria, de preceitos reducionistas. (LIPOVETSKY; CHARLES, 2018).

Ao trabalhar com a tese de Gilles Lipovetsky e descrever a atual concepção sociocultural da humanidade, chega-se ao fim deste primeiro capítulo. Antes de prosseguir, resgata-se alguns pontos que aqui foram trabalhados para uma melhor compreensão da discussão do próximo capítulo. Em síntese, viu-se, em Zygmunt Bauman (2001), que a sociedade passou por um processo de derretimento de seus institutos. Entretanto, ao passo em que a sociedade passou a admitir cada vez mais uma concepção diversificada sobre os seus institutos, houve uma elevação da carga de complexidade do mundo para uma dimensão jamais presenciada em toda a história da humanidade, surgindo, daí, a ideia da razão em sua forma estendida, afinal, a Modernidade Líquida passará a entrar em colapso a medida em que a sua descrição (razão líquida) se torna insuficiente para descrever aquilo que foi justamente ela que deu causa - numa perspectiva sistêmica, partindo-se de Rocha, Schwartz e Clam (2005), a autopoiese de Niklas Luhmann (2016) mostra que houve uma redefinição da perspectiva do sentido originário daquela linguagem-signo, ou seja, houve uma própria redefinição do sentido de cultura para a sua perspectiva de contar com valores amplos. Viu-se, então, ao final deste primeiro capítulo, que essa transição da razão líquida para a sua forma estendida que se vive atualmente é descrita pela tese da Hipermodernidade do filósofo francês Gilles Lipovetsky (2018): o que se vive atualmente é uma desorientação social referida ao fato de que a própria sociedade passou a admitir uma moldagem ampla dos seus institutos, afinal, os valores passaram a ser amplos. No capítulo seguinte, tomando-se por base toda a construção até então desenvolvida, será buscado um conceito de Processo condizente à esta realidade social.

\section{O HIPERPROCESSO, A HIPERJURISDIÇÃO E O CASO DO TRIBUNAL MULTIPORTAS DE ACESSO À ORDEM JURÍDICA DE FRANK SANDER: A SITUAÇÃO DO PROCESSO NOS TEMPOS HIPERMODERNOS DE GILLES LIPOVETSKY}

$\mathrm{Na}$ linha do que se vem construindo neste estudo, dado este momento em que se assume o objetivo de buscar apresentar um conceito atual de Processo, observa-se que as situações práticas recentes muito contribuem para lograr êxito em tal tarefa. Pegue-se, assim, inicialmente numa perspectiva judicial do Processo, o caso da emergência de uma vasta 
possibilidade de formas de resolver os conflitos sociais. Hoje, admite-se que as lides possam ser resolvidas por formas distintas em relação à jurisdição (heterocomposição), como é o caso da conciliação, da mediação, da arbitragem, e até mesmo de uma forma que o Estado brasileiro está, aos poucos, passando a dar a devida importância, no caso a constelação familiar. Este primeiro exemplo mostra que o mesmo peso dado à uma sentença judicial, é, de igual peso, dado à um acordo ou à uma sentença arbitral; aliás, não se buscando obstar esta primeira análise dada ao Processo, na Hipermodernidade de Gilles Lipovetsky (2018), pela perspectiva judicial, mas, o que se vê é que essa emergência de formas de resolução de conflitos alheias àquela jurisdição clássica do Estado é um tema que está cada vez mais em voga nos ambientes de formação dos cientistas jurídicos. Seja em salas de aula das faculdades de Direito, seja em cursos de capacitação para o exercício da profissão de conciliador ou mediador, ou ainda, vêse que os próprios livros de Direito Processual Civil passaram a incorporar capítulos específicos em seus volumes para trabalhar essas formas, enfim, o que se denota com tudo isso é que houve dentro e fora dos Tribunais uma abertura cognitiva à essa pluralidade de formas de resolver conflitos. Deste exemplo, questiona-se: por que houve essa abertura cognitiva às formas diversificadas de resolver conflitos? Pegue-se, agora, a situação do Processo dos tempos Hipermodernos numa perspectiva extrajudicial. Vê-se que, cada vez mais, determinados grupos da sociedade não mais estão recorrendo ao Poder Judiciário para a resolução de todos os seus conflitos. Neste ponto, a questão que se quer frisar é que não houve um desinteresse em exercer a garantia constitucional de acesso à justiça, mas sim que ela vem sendo exercida de forma extrajudicial. Pequenas comunidades, associações, bairros, enfim, estão cada vez mais a darem força para os seus respectivos "Códigos de Processo Civil". Não se trata de desprezar o direito posto, mas sim de uma fortificação que o pluralismo jurídico vem ganhando. Boaventura de Sousa Santos (1988) vê tal questão a partir do seu estudo realizado na comunidade, do Rio de Janeiro, de Pasárgada. A referida comunidade conta com a sua respectiva "legislação" processual, afinal, elegem a mediação como forma de resolver os conflitos dali oriundos que versam sobre questões, por exemplo, habitação. Ou seja, esse pluralismo processual faz perceber que o Processo, enquanto sua perspectiva de resolver conflitos, não mais está em sine qua non aos Tribunais para que possa existir. Deste exemplo, novamente, questiona-se: por que há, cada vez mais, codificações processuais civis “não oficiais"? 
Buscando-se responder ao questionado, o que se observa é que essa manifestação da cultura hipermoderna no Processo é vista na perspectiva de uma desorientação processual: houve uma ampliação da própria concepção que se deve ter por Processo. O que parece é que, de igual forma ao diagnóstico dado por Gunther Teubner (2016) sobre a situação do constitucionalismo contemporâneo, o Processo cada vez mais apresenta-se como fragmentado, ou seja, apresenta-se sem uma unidade central. Essa fragmentação refere-se ao fato de que atualmente o Processo não mais conta com uma estrutura tecnicamente delimitada - como era o caso do Processo em sua visão clássica -; a partir de seu processo de expansão, passasse a moldar de acordo com o surgimento de diversas peculiaridades nesta sociedade globalizada. Poliamor, bitcoins, homeoffice, webnamoro, empresas transnacionais com capital superior ao valor patrimonial de inúmeras nações, Constituições transnacionais e subnacionais, dentre inúmeros outros exemplos mostram que mesmo que haja uma proposta de delimitar o Processo, ela não proporcionará a devida efetividade que dele se espera, afinal, o Processo deve responder à todas essas situações. Outrossim, o Hiperprocesso refere-se à abertura cognitiva de uma concepção ampla de Processo, justamente para que se possa levar em conta a alta carga de complexidade que há atualmente no mundo. Portanto, o Processo passa a ser complexo para que, justamente como ensina Niklas Luhmann (2008), possa responder de forma a não simplificar essas novas moldagens dos institutos sociais, mas que, de igual forma ao cenário social, tenha uma estrutura teórica suficientemente complexa. Observar o Processo a partir de sua complexidade é, em síntese, permitir que ele possa responder à essa diversidade social que cresce a cada dia. Da concisão necessária que se buscou realizar neste parágrafo sobre uma concepção de um Hiperprocesso, a partir de agora, adentra-se no problema central deste artigo, no caso, buscar compreender como a jurisdição se manifesta nessa atual realidade de Processo.

Ao trabalhar com a temática da jurisdição no Hiperprocesso, deve-se destacar que não será levado em conta toda aquela discussão que poderia surgir acerca da manifestação desse Hiperprocesso em sua perspectiva extrajudicial. A discussão aqui iniciada refere-se ao fato do Hiperprocesso em sua perspectiva judicial, especialmente para que seja possível compreender uma nova roupagem da garantia fundamental de acesso à justiça disposta no art. $5^{\circ}$, inc. XXXV, da Constituição da República Federativa do Brasil de 1988, como já observado por Guilherme Christen Möller (2018). A análise do referido dispositivo constitucional não é despretensiosa, pelo contrário, afinal, como viu-se anteriormente neste mesmo capítulo, há, hoje, uma abertura cognitiva dos operadores do direito à uma visão plural das formas de resolver os conflitos 
sociais - eis o ponto que se busca trabalhar. Quer-se debater, portanto, se quando a Constituição Federal, no dispositivo referido alhures, sustenta que "a lei não excluirá da apreciação do Poder Judiciário lesão ou ameaça de direito", a tutela jurisdicional resguardada pelo Estado, na atual visão Hipermoderna da sociedade, refere-se unicamente à jurisdição ou também se refere à outras formas que já estão, de igual modo, chanceladas pelo Estado.

Sobre a garantia constitucional prevista no inc. XXXV, do art. $5^{\circ}$, da Constituição Federal, observa-se que se propala uma vulgata no meio acadêmico de que tal garantia, em verdade, possuí uma intrínseca - no sentido de exclusividade - ligação para com a defesa do acesso à ordem jurídica pela via da jurisdição. Nada mais falso. O problema que se vê na referida postura está em desconsiderar a principal faceta do Processo nesta perspectiva aqui proposta - ou seja, de um Processo enquanto um instrumento judicial de resolução de conflitos -: a sua efetividade. Para que o Processo, nessa perspectiva, possa alcançar a efetividade que dele se espera, deve-se sempre lembrar o ponto já destacado alhures neste texto: o Processo nada mais é do que um produto social; ou seja, vez que o Processo (e o Direito) nada mais é do que uma identificação cultural, deve-se, a todo momento, ser aplicado à luz da sua determinada realidade. Nesse sentido, por exemplo, pegue-se a utópica ideia de aplicar o Hiperprocesso em eventuais conflitos da Modernidade Sólida (renascentista); ou seja, aplicar o complexo ao simples (disjunto): há uma colisão de realidades culturais que determinará na insuficiência efetiva do Processo - a questão da insuficiência efetiva do Processo, ainda, poderia ser analisada dentro de uma respectiva fase sociocultural, no entanto, com valores comunitários distintos. $\mathrm{O}$ destacado aproxima-se muito à ideia de Montesquieu (2010), afinal, deve-se considera que a lei (no caso, o Direito e o Processo) deve ser rente à realidade (prática - costumes, crenças, valores, tradições...) do povo específico em que ela vigerá. A mesma análise deve ser feita ao observar a interpretação que se deve dar ao disposto no inc. XXXV, do art. $5^{\circ}$, da Constituição Federal: em tempos em que a carga de complexidade da sociedade assume uma dimensão jamais presenciada, há a possibilidade de interpretar a referida garantia constitucional tão somente em sua perspectiva reducionista?

Veja-se que a elevação da carga de complexidade da sociedade fará o caminho inverso ao de reduzir a quantidade de conflitos; verdade seja dita: há, e cada vez mais, uma vasta pluralidade de peculiaridades distintas nos diversos conflitos sociais. A composição dos elementos de cada um desses conflitos estão, paulatinamente, indo em sentido contrário ao de 
uma visão reducionista dos conflitos, como quer, neste segundo caso, uma visão generalista das formas de resolução de conflitos sobre os conflitos dessa sociedade complexa. Exemplificandose o problema que se vislumbra em tal cognição generalista, pegue-se o caso dos "meios adequados de solução de conflitos", representados pela sigla "MASC"; ao assumir-se a postura de estabelecer que existem formas mais adequadas de resolver os conflitos - como normalmente ocorre ao referir-se à mediação e à conciliação (autocompositivas) - do que outras, desprezase, em toda a sua completude, essa necessária visão policontextural que deve existir sobre os conflitos e as formas que existem para resolvê-los. Atualmente, versando-se acerca da temática do Processo aqui proposta, é impossível conceber critérios objetivos de "adequação", ou ainda de "alternatividade", entre as formas de resolução de conflitos. Para que o Processo possa, em tempos Hipermodernos, proporcionar a sua real efetividade, deve, a ele, associar essa visão policontextural, de Gunther Teubner (2005), dos conflitos sociais. Assim, ao considerar que o Estado é o guardião da tutela jurisdicional, deve, ele, levar em consideração a reflexão exposta no parágrafo anterior; ou seja, ao buscar-se resguardar a garantia constitucional do exercício da tutela jurisdicional, em tempos de uma Hipermodernidade, deve, tal garantia, ser interpretada à luz da realidade prática de seu tempo. Em tempos de um Hiperprocesso, deve, o Estado, garantir o exercício da tutela jurisdicional pelas diversas formas de resolução de conflitos que ele chancela (admite), de modo que, não apenas a jurisdição, mas, de igual forma, a conciliação, a mediação, a arbitragem e, até mesmo, a constelação familiar, devem ser tutelas como formas de acesso à ordem jurídica. O pensamento - não mais condizente com a atual realidade - de estabelecer uma objetividade de critério positivamente dispostos acerca dessa ou daquela forma de resolução de conflitos, seja para afirma-la como mais adequada, inadequada, exclusiva, alternativa, principal, enfim, deve ser substituída por uma postura cognitivamente aberta à abstração social causada pela complexidade; dito de outra forma, a jurisdição, enquanto uma garantia fundamental de acesso à ordem jurídica, deve sofrer uma abertura cognitiva à contemplar a adequação para a adequação, ou seja, são as respectivas peculiaridades de cada um desses conflitos que caracterizarão qual é a forma mais "adequada" para que ele possa ser dirimido, e não a postura impositiva (seja por lei ou qualquer ato público). Eis a amplitude que se deve dar à garantia do exercício jurisdicional na atual concepção social; eis, portanto, a ideia de uma hiperjurisdição.

Em que pese toda a análise até então desenvolvida, mesmo que muito pareça, a ideia de uma hiperjurisdição não deve ser confundida para com a ideia de um Tribunal Multiportas 
de Acesso à Ordem Jurídica - a tese desenvolvida pelo falecido professor da Escola de Negociação da Universidade de Harvard, Frank Sander -, vez que são as suas próprias características que evidenciarão essa cisão. Pegue-se, por um lado, e recapitulando o visto anteriormente neste mesmo capítulo, a ideia de uma hiperjurisdição; dado o aumento imensurável do nível de complexidade da sociedade, há a necessidade de que haja uma interpretação extensiva sobre àquele conceito clássico de jurisdição. Ou seja, aqui está se referindo, portanto, ao fato da existência de uma ampliação acerca da interpretação que se deve operar sobre a garantia da tutela jurisdicional - e não da própria jurisdição como forma de resolver conflitos - para que ela seja, efetivamente, suficiente à realidade cultural momentânea social. Agora, por outro lado, a tese proposta por Frank Sander, o Tribunal Multiportas, tratase de uma teoria desenvolvida ao acaso, como ele mesmo explica em uma entrevista com Mariana Hernandez Crespo (2012), cujo pensamento refere-se ao fato de, dada a crise relativa ao número de processos judiciais tramitando nos Tribunais de Justiça dos Estados Unidos da América ao longo das últimas décadas do milênio passado, viabilizar aos litigantes a existência de formas "alternativas" de resolver os conflitos, como o caso da mediação, da negociação, da "med-arb", negociação, dentre outros. Como fica esclarecido na referida entrevista entre os professores Sander e Crespo (2012), a tese proposta pelo professor da Escola de Negociação da Universidade de Harvard não está desenhada na proposta que se quer para a interpretação da jurisdição sob a ótica da Hipermodernidade, justamente o contrário: cai-se em uma generalização dada às formas de resolução de conflitos, afinal, a tese lapida-se na concepção de que há, no caso a jurisdição, uma forma "principal” de resolver os conflitos - a qual, dada a alta taxa de processos judiciais movidos, provocou o colapso no sistema de justiça estadunidense , enquanto as demais são, em verdade, alternativas à crise ocasionada em decorrência daquela; mais do que isso, é essa "alternatividade" a proposta para combater a referida crise. Entretanto, o ponto que afastará a hiperjurisdição da tese do Tribunal Multiportas é o fato de que, ao referirse à hiperjurisdição, na perspectiva judicial do hiperprocesso, a situação deve ser posta ao conhecimento do Poder Judiciário, afinal, é ele que apresentará um mecanismo de gerenciamento desses conflitos à ele propostos a partir das formas de resolução de conflitos que ele conhece, situação completamente distinta ao Tribunal Multiportas, vez que, neste último, busca-se estabelecer um centro de triagem apartado em relação ao Poder Judiciário. 
Desse modo, ao final deste estudo, buscando-se realizar uma síntese e uma conexão entre os principais pontos - principalmente os vistos neste segundo capítulo -, o que se observa é, ao trabalhar com a temática Hipermodernidade e Processo, sob o pretexto de lograr êxito numa concepção atual de Processo, obtêm-se a ideia de um Hiperprocesso, uma hiperjurisdição e, de à limiar, explora-se a tese de Frank Sander sobre o Tribunal Multiportas de Acesso à Ordem Jurídica, como uma possível representação dessa última ideia de hiperjurisdição; ocorre, no entanto, que se tratam de questões distintas. A partir de toda a construção realizada, principalmente no primeiro capítulo deste estudo, pode-se delimitar a ideia de um Hiperprocesso sob a ótica judicial e extrajudicial, de modo que, enquanto a sua ótica extrajudicial, brevemente analisada, está relacionada à uma fragmentação processual dada a perda de uma unidade central do Processo, especialmente diante de uma elevação dos níveis de complexidade da sociedade; essa mesma complexidade determinará a sua faceta judicial, representada pela ampliação cognitiva da garantia fundamental de acesso à ordem jurídica, a qual, para fornecer uma concepção igualmente complexa à realidade da sociedade, passa a admitir o desenvolvimento da garantia à tutela jurisdicional - no caso do Brasil, com o caso do inc. XXXV, do art. $5^{\circ}$, da Constituição Federal de 1988 - por vias de outras formas de resolver os conflitos, contanto que chanceladas pelo Estado. A tese de Frank Sander, mesmo que louvável e muito à frente do tempo em que fora concebida, não representa essa perspectiva judicial do Hiperprocesso, afinal, ao passo em que se quer conceber uma ideia condizente de hiperjurisdição, deve-se considerar, de partida, que qualquer que seja a teoria utilizada e que está embasada em pressupostos generalistas, caminha em sentido antagônico ao da caracterização da tutela jurisdicional em tempos Hipermodernos. Quiçá, o próprio modelo do Tribunal Multiportas, com as devidas adaptações cognitivas, a partir de incentivos em políticas públicas nacionais voltadas à real concretização dessa visão atual de Processo, poderá ser um caminho para essa teoria tornar-se práxis, entretanto, esses desafios são um tema para um outro estudo.

\section{CONCLUSÃO}

Ao final deste estudo, espera-se ter respondido ao problema desta pesquisa. Num primeiro momento deste estudo, da análise da relação umbilical entre a Cultura e o Processo, viu-se que, atualmente, dada a dimensão que a razão vem tomando, ou seja, ampliando-se cada 
vez mais, não mais há a possibilidade de que se fixe parâmetros mínimos e máximos sobre os institutos da sociedade; os institutos da sociedade passam para uma forma mais ampla e o atual retrato social é visto na tese defendida pelo filósofo francês Gilles Lipovetsky sobre a Hipermodernidade, ou seja, da formação da ideia de cultura a partir de uma tríplice caracterização: o mercado (capitalismo); a tecnologia; e, o indivíduo. Vê-se que a despadronização completa dos institutos da sociedade é a manifestação pura de que a humanidade conseguiu desvencilhar-se, em sua maioria, de preceitos reducionistas. Dessa análise, partiu-se para a análise da atual concepção de Processo e de Jurisdição.

Num segundo momento, a cultura hipermoderna no Processo é vista na perspectiva de uma desorientação processual: houve uma ampliação da própria concepção que se deve ter por Processo. O Processo cada vez mais apresenta-se como fragmentado, ou seja, apresenta-se sem uma unidade central. Essa fragmentação refere-se ao fato de que atualmente o Processo não mais conta com uma estrutura tecnicamente delimitada - como era o caso do Processo em sua visão clássica -; a partir de seu processo de expansão, passasse a moldar de acordo com o surgimento de diversas peculiaridades nesta sociedade globalizada. Poliamor, bitcoins, homeoffice, webnamoro, empresas transnacionais com capital superior ao valor patrimonial de inúmeras nações, Constituições transnacionais e subnacionais, dentre inúmeros outros exemplos mostram que mesmo que haja uma proposta de delimitar o Processo, ela não proporcionará a devida efetividade que dele se espera, afinal, o Processo deve responder à todas essas situações. Outrossim, o Hiperprocesso refere-se à abertura cognitiva de uma concepção ampla de Processo, justamente para que se possa levar em conta a alta carga de complexidade que há atualmente no mundo. Portanto, o Processo passa a ser complexo para que possa responder de forma a não simplificar essas novas moldagens dos institutos sociais, mas que, de igual forma ao cenário social, tenha uma estrutura teórica suficientemente complexa. Observar o Processo a partir de sua complexidade é, em síntese, permitir que ele possa responder à essa diversidade social que cresce a cada dia.

Portanto, ao final deste estudo, conclui-se que, ao trabalhar com a temática Hipermodernidade e Processo, sob o pretexto de lograr êxito numa concepção atual de Processo, obtêm-se a ideia de um Hiperprocesso, uma hiperjurisdição e, de à limiar, explora-se a tese de Frank Sander sobre o Tribunal Multiportas de Acesso à Ordem Jurídica, como uma possível representação dessa última ideia de hiperjurisdição. Assim, pode-se delimitar a ideia 
de um Hiperprocesso sob a ótica judicial e extrajudicial, de modo que, enquanto a sua ótica extrajudicial está relacionada à uma fragmentação processual dada a perda de uma unidade central do Processo, especialmente diante de uma elevação dos níveis de complexidade da sociedade; em sua faceta judicial, representada pela ampliação cognitiva da garantia fundamental de acesso à ordem jurídica, a qual, para fornecer uma concepção igualmente complexa à realidade da sociedade, passa a admitir o desenvolvimento da garantia à tutela jurisdicional por vias de outras formas de resolver os conflitos, contanto que chanceladas pelo Estado. A tese de Frank Sander, no entanto, não representa essa perspectiva judicial do Hiperprocesso, afinal, ao passo em que se quer conceber uma ideia condizente de hiperjurisdição, deve-se considerar, de partida, que qualquer que seja a teoria utilizada e que está embasada em pressupostos generalistas, caminha em sentido antagônico ao da caracterização da tutela jurisdicional em tempos Hipermodernos. Quiçá, o próprio modelo do Tribunal Multiportas, com as devidas adaptações cognitivas, a partir de incentivos em políticas públicas nacionais voltadas à real concretização dessa visão atual de Processo, poderá ser um caminho para essa teoria tornar-se práxis, entretanto, esses desafios são um tema para um outro estudo.

\section{REFERÊNCIAS}

ALMEIDA, Rafael Alves de; ALMEIDA, Tania; CRESPO, Mariana Hernandez (orgs.). Tribunal Multiportas: investindo no capital social para maximizar o sistema de solução de conflitos no Brasil. Rio de Janeiro: Editora FGV, 2012.

BAUMAN, Zygmunt. Modernidade Líquida. Trad. Plínio Dentzien. Rio de Janeiro: Zahar, 2001.

. A cultura no mundo líquido moderno. Trad. Carlos Alberto Medeiro. Rio de Janeiro:

Zahar, 2013.

CARNELUTTI, Francesco. Arte do Direito. São Paulo: Editora Pillares, 2007. 
CHASE, Oscar G. Direito, Cultura e Ritual: sistemas de resolução de conflitos no contexto da cultura comparada. Trad. Sergio Arenhart e Gustavo Osna. São Paulo: Marcial Pons, 2014.

CÍCERO, Marco Túlio. Das Leis. Trad. Otávio T. de Brito. São Paulo: Cultrix, 1967.

DESCARTES, René. Discurso sobre o Método. 2. ed. Trad. Alan Neil Ditchfield. Petrópolis: Vozes, 2011.

Meditações Metafísicas. Trad. Edson Bini. São Paulo: Edipro, 2016.

GADAMER, Hans-Georg. Verdade e Método. Trad. Flávio Paulo Meurer. 7. ed. Petrópolis: Vozes, 2005. v. 1: traços fundamentais de uma hermenêutica filosófica.

GRUPPI, Luciano. Tudo começou com Maquiavel: As concepções de Estado em Marx, Engels, Lênin e Gramsci. 14. ed. Porto Alegre: L\&PM, 1996.

HELLER, Hermann. Teoria do Estado. Trad. Lycurgo Gomes da Motta. São Paulo: Mestre Jou, 1968.

LACERDA, Galeno. Teoria Geral do Processo. Rio de Janeiro: Forense, 2008.

LIEBMAN, Enrico Tullio. Manual de Direito Processual Civil. Trad. Cândido Rangel Dinamarco. 3. ed. São Paulo: Malheiros, 2005, v. 1.

LIPOVETSKY, Gilles. A felicidade paradoxal: ensaio sobre a sociedade de hiperconsumo. Trad. Maria Lucia Machado. São Paulo: Companhia das Letras, 2007.

LIPOVETSKY, Gilles; SERROY, Jean. A cultura-mundo: resposta a uma sociedade desorientada. Trad. Maria Lúcia Machado. São Paulo: Companhia das Letras, 2011. 
LIPOVETSKY, Gilles; CHARLES, Sébastien. Os tempos hipermodernos. Lisboa: Edições 70, 2018.

LUHMANN, Niklas. La sociedad de la sociedad. Ciudad Del México: Herder, 2008.

O direito da sociedade. Trad. Saulo Krieger. São Paulo: Martins Fontes, 2016.

MACHIAVEL, Nicolau. O príncipe. Edição eletrônica, Ed. Ridendo Castigat Mores, 2005.

Disponível em: <http://www.ebooksbrasil.org/adobeebook/principe.pdf〉. Acesso em: 9 mar. 2019.

MÖLLER, Guilherme Christen. Pontos controversos sobre o Código de Processo Civil de 2015. Curitiba: Prismas, 2018.

MONTESQUIEU, Charles. Do espírito das leis. Trad. Roberto Leal Ferreira. São Paulo: Martin Claret, 2010.

MORIN, Edgar. Introdução ao pensamento complexo. Trad. Eliane Lisboa. 5. ed. Porto Alegre: Sulina, 2015.

POPPER, Karl Raimund. Textos escolhidos. Trad. Vera Ribeiro. Rio de Janeiro: Contraponto: Ed. PUC-Rio, 2010.

RIBEIRO, Darci Guimarães. Da tutela jurisdicional às formas de tutela. Porto Alegre: Editora Livraria do Advogado, 2010.

ROCHA, Leonel Severo; SCHWARTZ, Germano; CLAM, Jean. Introdução à teoria do sistema autopoiético do Direito. Porto Alegre: Editora Livraria do Advogado, 2005.

SANTOS, Boaventura de Sousa. O discurso e o poder: ensaios sobre a sociologia da retórica jurídica. Porto Alegre: Sérgio Antônio Fabris Editor, 1988. 
SARLET, Ingo Wolfgang. Maquiavel, “O Príncipe” e a formação do Estado Moderno. Porto Alegre: Editora Livraria do Advogado, 2017.

SPIRO, Melford E. Culture and Human Nature. rev. ed. Bejamin Killborne and L.L. Langness, eds. Piscataway, NJ: Transaction Publishers, 1994.

STJ. Recurso Especial: REsp n. 1.713 .167 (2017/0239804-9). Relator: Min. Luis Felipe Salomão. Superior Tribunal de Justiça, 2017. Disponível em: $<$ https://ww2.stj.jus.br/processo/pesquisa/?tipoPesquisa=tipoPesquisaNumeroUnico\&termo=1 0003988120158260008\&totalRegistrosPorPagina=40\&aplicacao=processos.ea $>$. Acesso em: 15 mar. 2019.

STRECK, Lenio Luiz. Dicionário de Hermenêutica: quarenta temas fundamentais da Teoria do Direito à luz da Crítica Hermenêutica do Direito. Belo Horizonte: Casa do Direito, 2017.

TEUBNER, Gunther. Direito, Sistema e Policontexturalidade. Piracicaba: Editora Unimep, 2005.

Fragmentos constitucionais: constitucionalismo na globalização. São Paulo: Saraiva, 2016. 